\title{
Construction of the "Value Chain of Credit"
}

\author{
Yu-han Wang
}

School of economics and management, Shanghai second polytechnic University, Shanghai, China

\begin{abstract}
Credit Activities and Behavior of credit is the carrier of a market economy. Actors in the realization of economic activities on the value chain to identify create and add value through credit activities. There is a value chain of credit in economic activity. We can maintain the credit value chain relationships methods include: Establish a evaluation system of credit, Establish a database of credit, Specification of credit products and so on. Constraints actors act in the value chain of credit, create credit order to improve the efficiency of credit transactions. This paper focuses on connotation value chain of credit, Upstream and downstream relationships in value chain of credit, important issue in the value chain of credit formation.
\end{abstract}

Keywords - Value chain of credit, Evaluations system of credit metrics, credit products

\section{构建“信用价值链”初探}

\author{
汪宇瀚 \\ 经济管理学院, 上海第二工业大学, 上海, 中国 (hylandwang@ 163.com)
}

摘 要 信用活动和信用行为用以支撑现代市场经济运行, 脱离信用活动, 市场经济则不复存在。处在经济活动上下游的行为主 体, 通过信用行为的发生, 实现了在传统产业链上的价值发现、创造及增值。即, 可以理解为在经济活动中存在有一个信用价值链。 有必要通过信用指标评价体系和数据库的建立、规范化的信用产品的设计及交换来维护信用价值链关系, 通过制度约束价值链中行为 主体的信用行为, 塑造信用经济秩序, 提高信用交易效率。文章从信用价值链的内涵、信用价值链的上下游关系及在信用价值链形成 中需要重视的问题入手展开论述。

关键词＼cjkstart信用价值链，信用指标评价体系，信用产品

2013 年 10 月, 注册资本登记制度改革, 企业年检制 度更改为年度报告制度。可预见当实际经济行为与监督检 查出现时间上的分离构成经济行为发生主体是否能够履约 的客观环境, 即存在一定的信用行为。

\section{1. 信用价值链的内涵}

\section{1 企业信用价值链的内涵}

信用价值链是指以信用行为的发生为线索，架构起的 各类信用主体的上下游关系。

信用价值链上游的行为主体，通过中间信用产品的设 计, 朝其下游信用行为主体转移产品, 并实现其价值发现、 创造及增值。

\section{2 传统产业链中存在信用价值链}

价值链在经济活动中是无处不在的，企业内部各业务 单元之间存在着内部价值链, 上下游关联的企业与企业之 间存在行业价值链, 还有竞争对手价值链和顾客价值链等。 在价值链管理中，企业处于价值增值考虑，会主动完成价 值链的协调和优化, 主动处理和协调企业上游、下游价值 链的合作关系。

构造信用价值链关系, 是基于产业链理论上的一个创 新应用，原理有相通性。

传统产业链形成的原因在于通过这种企业间的关联， 其产业价值能够得以实现。创造产业链是产业价值实现和 增值的根本途径。

项目资助编号: XXKPY1306 (上海第二工业大学金融学培育学科) 
类似传统产业链，信用价值链实质是不同行为主体间 存在信用上的关联性，而这种信用关联的实质则是各产业 中的行为主体通过各类信用中间、终端产品构建起的上下 游关系。

企业通过利用信用价值链关系来整合上下游资源, 约 束自身信用行为, 以便在信用价值链上处于有利位置, 获 取更大的价值增值。

按照先进的信用管理理念, 信用发生主体维持、提升 自身信用级别的动力在于该信用级别的提升，必须通过特 定的载体为其带来价值实现和增值, 这特定载体表现为信 用价值链中的各类信用产品，信用产品是具有价值和使用 价值的特殊商品, 存在于整个信用价值链中。

传统产业链的实质是不同产业的企业之间的关联，而 这种产业关联的实质则是各产业中的企业之间的供求关 系。

同样，创造信用价值链，可将反映在传统产业链中的 产业价值转换到信用产品的价值中，任何信用价值的显现 及增值应该通过信用产品消费实现，包括处于信用价值链 的中间产业价值的计量, 也均以信用产品消费为前提。

\section{2. 信用价值链中的主要上下游关系}

\section{1 信用价值链系统外设国家监管}

由国家有关机构、央行、部委等负责法律、规则的制 定，信用标准的设计，信用数据收集、传输和存储等统一 接口，失信惩戒分为失信经济惩戒与非经济惩戒两类。失 信非经济类惩戒包括：行政、司法惩戒等，国家监管负责 该职责的履行。在构建信用价值链后, 对失信行为的经济 惩戒应该通过价值链体系内信用产品享有、失信成本的放 大等市场手段予以实现。

\section{2 信用信息数据库的运行}

通过国家主导的数据库、市场化的各类信用信息数据 库集成而得。该数据库应当具有接口规范，以便数据后期 的加工、传输和使用。

\section{3 授信及信用服务机构}

\section{1）第二方授信机构}

其一，主要负责设计各类终端信用产品，并以此在市 场上通过销售给信用产品需求方而获利。其二，在授信完 成后可以依托信用终端产品设计信用打包产品, 并寻找相 关需求者，实现后期风险管理。

\section{2）第三方信用服务机构}

以中介身份参与信用价值链活动，通过提供信用中间 产品, 并合法销售给相关产品需求方以获取价值增值。

其余信用价值链中的关系见图 1 所示。

\section{3. 信用价值链形成中的关键问题}

通过关键点的把握来构建信用价值链。

\section{1 信用评价指标体系的设计}

信用评价指标体系是完成数据库建设, 信息收集、加 工、整理和传输的关键, 也是各级、各类信用信息数据库 能够得以统一接口对接的保证。依惯例, 我们会将资金往 来的活动作为信用评价指标体系的构成。事实上，如配合 信用价值链的设计，可修正原信用评价因素。

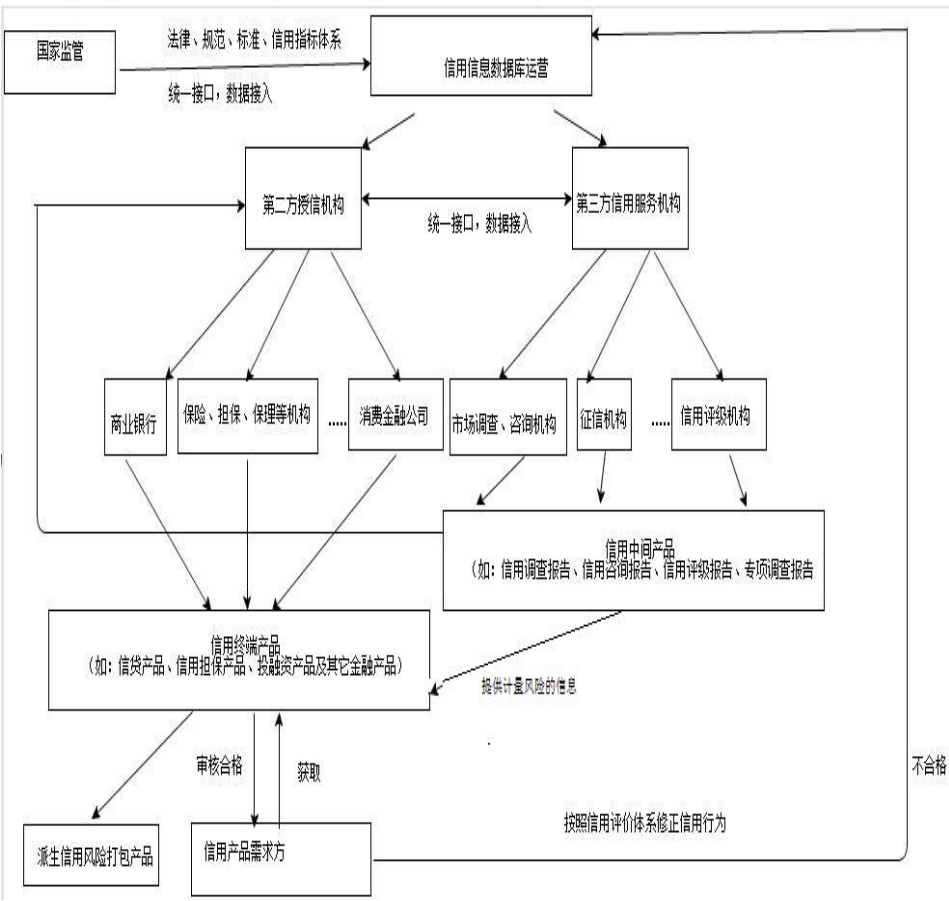

图 1. 信用价值链关系

完整的信用评价指标体系，内容包括：

\section{1 .1 金融信息}

（1）以往支付历史。包括：各种账户的支付信息; 负 面公共记录以及诸如破产、抵押、诉讼、留置等报告事项, 账户及应付款的违约情况以及公共记录的细节; 支付账户 未出现延期的天数。

（2）信贷欠款数额。包括: 各种不同类型账户的欠款 数额; 特定类型账户的信贷余额、有信贷余额的账户的数 
目; 信用额度使用比例、分期付款余额与原始贷款数额比 例。

(3) 账户数目和使用时间、频率。包括: 该客户拥有 的信用账户类型、数目，信用账户开立的最早、平均时间; 特定信用账户开立时间; 客户使用某账户的频率、最近查 询记录等。

\section{1 .2 商务信息}

（1）即时商务活动的履约情况。

即时商务活动, 即可以理解为通俗所谓的“一手交钱一 手交货”。即时商务活动同样存在是否按照合同履约的信用 行为。需要建立合同履约记录, 即记录是否存在违反商务 合同的行为。这里的合同，既包括当事人签订的文本合同 也包括在一般贸易活动中买卖双方以支付、获取商品劳务 而形成的实际、口头约定。

包括:

其一，产品或劳务的提供在质量、售后等方面是否按 约定达标。

其二，商务款项的结算是否按合同履约。

无论何种合同的当事人必须遵守的合同中应尽义务。 信用评价体系中需要考虑合同总量及其中实际构成违约的 数量及占比。

(2) 延时商务活动中收付信息。

延时商务活动的特征是存在资金结算与实际商品、劳 务交付在时间上的分离。

包括:

其一，预收款项能否按约交付实际商品、劳务的记录。

其二, 获取实际商品、劳务后的应付款项能否按约支 付的记录。

其三，一旦出现逾期交付或支付时采取变更、弥补的 对策操作的记录。

（3）作为信用产品需求方这一主体能够证明其商务信 用的其它信息。包括：

产品和劳务在生产、制造和提供中，是否存在欺瞒、 虚假记录, 是否有过交易纠纷记录等, 以及该部分负面信 息占总体信息量之比。

\section{1 .3 其它传统的信用信息}

包括行为主体的公共信用记录、偿债能力、资金实力 及状况、担保等因素和条件及行为主体所处行业、宏观等 因素变化的影响。

综上，笔者认为完整的信用评价指标体系应如表 1 所 示。
表 1 . 信用评价指标体系的内容

\begin{tabular}{|c|c|c|c|}
\hline 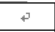 & 涵义 & 内容 & 主要负面记录表现 \\
\hline \multirow{5}{*}{$\begin{array}{l}\text { 金融 } \\
\text { 信息 }\end{array}$} & \multirow{5}{*}{$\begin{array}{l}\text { 与金融机构 } \\
\text { 之间的各类 } \\
\text { 往来记录 }\end{array}$} & 以往支付 & 逾期贷款 \\
\hline & & 信货记录 & 账户违规 \\
\hline & & 账户使用 & 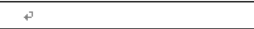 \\
\hline & & 债券等证券往来 & $p$ \\
\hline & & 担保活动记录 & $p$ \\
\hline \multirow{7}{*}{ 商务 } & $\begin{array}{l}\text { 与交易对手 } \\
\text { 之间的往来 } \\
\text { 记录 }\end{array}$ & 内容 & 主要负面记录表现 \\
\hline & \multirow{3}{*}{$\begin{array}{l}\text { 1、即时商务 } \\
\text { 活动 }\end{array}$} & 产品、劳务提供记录 & 产品、劳务末达约定标准 \\
\hline & & 商务款项结算记录 & 实际结算与约定不符 \\
\hline & & 其它 & 4 \\
\hline & \multirow{3}{*}{$\begin{array}{l}\text { 2、延时商务 } \\
\text { 活动 }\end{array}$} & 预收款项下产品、劳务的交付记录 & 产品、劳务未达约定标准 \\
\hline & & $\begin{array}{l}\text { 商品、劳务提供后应付款项的支付记 } \\
\text { 录 }\end{array}$ & 逾期商务款项 \\
\hline & & 其它 & + \\
\hline \multirow{5}{*}{ 公共 } & \multirow{5}{*}{$\begin{array}{l}\text { 与政府管理 } \\
\text { 部门、机构 } \\
\text { 等往来记录 }\end{array}$} & 税收支付 & 偷漏税 \\
\hline & & 工商记录 & 海关查验不良记录 \\
\hline & & 海关记录 & 兼并、破产、合同纠纷等记录 \\
\hline & & 司法记录 & $\begin{array}{l}\text { 第三方机构出具质黑抽检不合 } \\
\text { 格记录 }\end{array}$ \\
\hline & & 质量监督、抽检记录 & 垄断、不正当竞争等记录 \\
\hline \multirow{5}{*}{$\begin{array}{l}\text { 其它 } \\
\text { 传统 } \\
\text { 信用 } \\
\text { 信息 }\end{array}$} & \multirow{5}{*}{$\begin{array}{l}\text { 用以验证行 } \\
\text { 为主体信用 } \\
\text { 情况的信息 }\end{array}$} & 资金状况 & 虚假资金记录 \\
\hline & & 资金实力 & 重复担保 \\
\hline & & 担保情况 & 偿债违约 \\
\hline & & 偿债能力 & 2 \\
\hline & & 行业、宏观经济因素 & 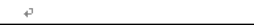 \\
\hline
\end{tabular}

\section{2 市场监管与政府监管之间的关系}

信用秩序的监管应由政府监管和市场监管共同完成。 其中，政府监管应处于宏观管理的位置，主要完成法律、 制度设计, 司法等监管工作。而大量存在于信用价值链各 端的微观行为主体之间的信用行为, 应该通过市场监管来 完成其信用行为约束。二者相辅相成, 政府、国家职能部 门的监管处于信用价值链体系外部，而市场监管则属于信 用价值链体系中内部自动恢复机制。

笔者认为, 惟有在信用价值链的背景之下，任何信用 活动将通过信用评价指标体系在信息数据库中予以记载, 而该评价指标体系将直接形成信用中间产品, 并成为行为 主体能否享有各类信用终端产品的参考值的情况下，市场 监管才能真正通过信用价值链得以实现。(图 2)

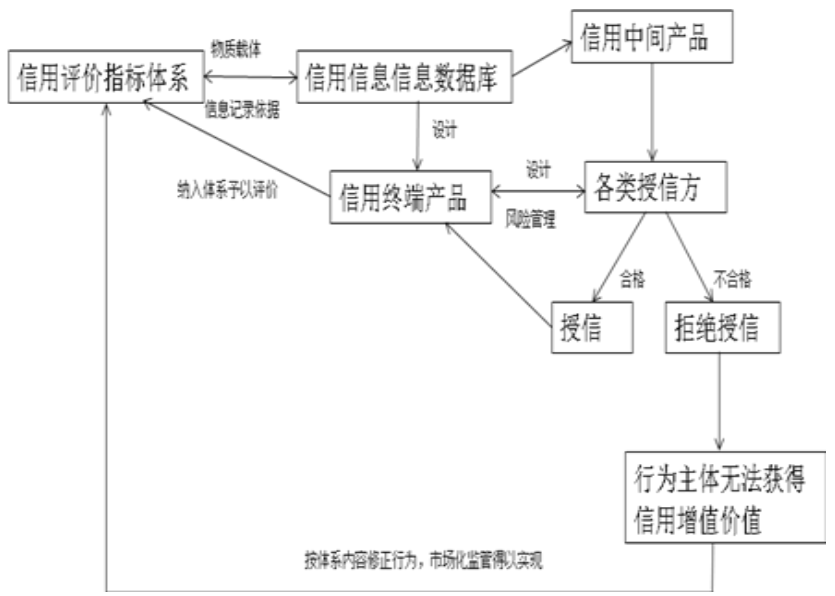

图 2: 市场化监管的自动机制 


\section{3 信用信息数据库接口对接设计}

由于目前信用信息存在包括央行负责的国家一级、各 部委一级、及市场行为主体一级的多级分散式特征, 故其 会影响到信用主体通过信用价值链体系获取价值增值的效 率。基于此, 笔者提出:

1）设计系列标准

笔者建议依托信用评价指标体系设计信用信息数据库 的数据管理标准、接口标准、传输标准等。

2) 拆分信用评价指标体系内容, 将其归口于各责任管 理部门或机构

除目前运行比较完善的央行负责的国家一级的两个信 用信息数据库以外,笔者认为值得一提的经验是, 早在 2011 年，国家工商管理总局就提出“信用分类监管”的思路。希 望通过建立健全信用分类监管体制机制，逐步深化联网应 用, 加大信用激励和信用约束力度, 不断提高市场监管效 能，积极营造良好的市场交易秩序和社会信用环境。工商 管理总局的方法, 按照守法诚信情况, 将企业分为 A、B、 C、D 四类，并采取不同的监管措施。在此基础上，根据监 管需要，进一步完善充实信用分类监管标准，健全完善“国 家经济户籍库”。国家工商管理总局系统管理的这部分信 息，与笔者设计的信用评价指标体系的商务信息及公共信 用信息中的一部分相吻合。

同样的思路，可以将信用评价指标体系中的内容予以 拆分, 归属给税务、海关等各部门来负责其中一部分内容 的记录。

3) 最终以国家一级的数据库作为物质平台予以归纳、 汇总

信用评价指标体系中的内容在经过拆分负责后，由国 家一级的数据库予以汇总、加工成以行为主体为单位的完 整记录。

4）合法通过“代码”查询行为主体的信息记录，信用终
端产品交易中需提供“代码”查询的授权。

国家一级的数据库在以行为主体为单位归集信息之 后，因选择给予数据库中每个行为主体一个“独一无二”的 数据备查“代码”。通过该代码可以查询到行为主体的信用 行为记录。可以要求在信用终端产品的提供前强制规范提 供相应的信用中间产品或“代码”查询的授权以资证明。

\section{4 信用终端产品的系统设计问题}

在信用价值链中, 价值增值需要通过特定载体来实现。 该特定载体即为“信用终端产品”。按现有的信用终端产品 来看, 目前存在有产品陈旧、单一, 产品的提供并未完全 与信用记录相结合, 产品后期的风险管理手段比较传统等 缺陷。

在信用终端产品设计上, 实质是一个系统问题, 需要 融合包括信用中间产品的使用、信用“代码”备查制度的建 立等多方面的问题，由于此问题所占篇幅过大，与本文主 题略有不符，故笔者考虑另行撰文探讨。

综上, 构建信用价值链关系, 将经济行为归口在信用 指标体系下记载, 并以此作依据, 使得处于信用价值链中 的各主体主动规范经济行为来获得信用产品, 实现信用价 值增值。

\section{参考文献(References)}

[1] LIU Meng-hao, Based on the value chain of commercial credit costs and benefits issues Commercial Accounting, Nov, 2012, pp80-81.

[2] YIN Qi-yue, Credit value and sustainable development of SME financing Commercial Research, May, 2013, pp73-79.

[3] LIU Yi-yan, WANG Sheng-jin, Mobile Financial Industry Chain Based on the Context of Information Technology, Information Science, May ,2013, pp138-141. 